\title{
A large-scale observational study linking various kinds of physical exercise to lipoprotein-lipid profile
}

\author{
Wan-Yu Lin ${ }^{1,2}$
}

\begin{abstract}
Background: Being a major cardiovascular risk factor, dyslipidemia is a critical problem in public health. Recommendations in performing regular physical exercise are important to prevent dyslipidemia.

Methods: Based on a discovery cohort with 27,735 subjects and a replication cohort with 67,512 subjects, we evaluated the associations of regularly performing 23 exercises with 4 dyslipidemia indices measured from serum, including triglyceride $(T G)$, low-density lipoprotein cholesterol (LDL-C), high-density lipoprotein cholesterol (HDL-C), and TG/HDL-C ratio. Regular exercise was defined as performing 30 min of "exercise" three times a week. "Exercise" includes leisure-time activities such as jogging, swimming, etc. Sex, age, body mass index, alcohol drinking, cigarette smoking, and education level were adjusted in all statistical analyses.

Results: Among the 23 exercises, only jogging was associated with a decreased level of TG (95\% confidence interval $[\mathrm{C} . \mathrm{I}]=.5.9-14.5 \mathrm{mg} / \mathrm{dL})$ and TG/HDL-C ratio $(95 \%$ C.I. $=0.22-0.49)$. A total of 5 exercises were associated with an increased level of HDL-C, including jogging ( $95 \%$ C.I. $=2.1-3.3 \mathrm{mg} / \mathrm{dL})$, swimming ( $95 \%$ C.I. $=1.6-3.3 \mathrm{mg} / \mathrm{dL})$, dance dance revolution (95\% C.I. $=1.5-3.4 \mathrm{mg} / \mathrm{dL}$ ), international standard dancing (95\% C.I. $=1.0-2.7 \mathrm{mg} / \mathrm{dL}$ ), and cycling (95\% C.I. $=0.6-1.8 \mathrm{mg} / \mathrm{dL})$. These significant findings were further well replicated in the cohort of 67,512 subjects.

Conclusion: Regular jogging was not only associated with an increased level of HDL-C, but also the only one exercise associated with a decreased level of TG and TG/HDL-C ratio. Nonetheless, jogging may be difficult to engage in for subjects with limited exercise capacity. We here found that swimming, dancing, and cycling are also significantly associated with an increased level of HDL-C. People who are seeking exercise to improve their lipoprotein-lipid profiles can have other choices now.
\end{abstract}

Keywords: High-density lipoprotein cholesterol, Jogging, Low-density lipoprotein cholesterol, Sport, Triglyceride

Correspondence: linwy@ntu.edu.tw

${ }^{1}$ Institute of Epidemiology and Preventive Medicine, College of Public Health,

National Taiwan University, Room 501, No. 17, Xu-Zhou Road, Taipei 100,

Taiwan

${ }^{2}$ Department of Public Health, College of Public Health, National Taiwan

University, Room 501, No. 17, Xu-Zhou Road, Taipei 100, Taiwan

C C The Author(s). 2021 Open Access This article is licensed under a Creative Commons Attribution 4.0 International License, which permits use, sharing, adaptation, distribution and reproduction in any medium or format, as long as you give appropriate credit to the original author(s) and the source, provide a link to the Creative Commons licence, and indicate if changes were made. The images or other third party material in this article are included in the article's Creative Commons licence, unless indicated otherwise in a credit line to the material. If material is not included in the article's Creative Commons licence and your intended use is not permitted by statutory regulation or exceeds the permitted use, you will need to obtain permission directly from the copyright holder. To view a copy of this licence, visit http://creativecommons.org/licenses/by/4.0/. The Creative Commons Public Domain Dedication waiver (http://creativecommons.org/publicdomain/zero/1.0/) applies to the data made available in this article, unless otherwise stated in a credit line to the data. 


\section{Background}

Dyslipidemia is an unhealthy level of lipids in blood, including elevated triglyceride (TG) or low-density lipoprotein cholesterol (LDL-C), and decreased high-density lipoprotein cholesterol (HDL-C). Moreover, the ratio of TG to HDL-C (TG/HDL-C ratio) is a useful indicator to detect metabolic syndrome [1].

Around $\sim 25 \%$ of people in the United States are living with hypertriglyceridemia (TG $>150 \mathrm{mg} / \mathrm{dL}$ ), which is a type of dyslipidemia and is associated with an increased risk of cardiovascular diseases [2]. According to the Ministry of Health and Welfare in Taiwan, a TG level > $150 \mathrm{mg} / \mathrm{dL}$; an LDL-C level $>130 \mathrm{mg} / \mathrm{dL}$; a HDL-C level $<40 \mathrm{mg} / \mathrm{dL}$ for males or a HDL-C level $<50 \mathrm{mg} / \mathrm{dL}$ for females, are considered dyslipidemia. As a major cardiovascular risk factor, dyslipidemia is a critical problem in public health. Lifestyle modification such as performing physical exercise is a low-cost and nonpharmacological strategy to improve one's lipoproteinlipid profile.

Studies have shown that TG decreased and HDL-C increased after $24 \mathrm{~h}$ of aerobic exercise training, and lasted through $48 \mathrm{~h}$ [3]. Some studies found that HDL-C is more sensitive to aerobic exercise than TG and LDL-C [4]. Regular exercise increases the level of HDL-C in a dose-response manner [5-8]. Almost all studies indicated that exercise increases HDL-C to some degree, which is a consistent result from both human [4, 9-13] and rats [14-16]. Moreover, regular exercise was found to improve "cholesterol efflux capacity", the ability of HDL-C to carry cholesterol from one's bloodstream to the liver for clearance [17].

Different from HDL-C, exercise effects on LDL-C have been inconsistent across studies. Some studies even provided completely contradictory results $[4,9-12]$. It has been suggested that exercise alone may not lower LDL$\mathrm{C}$, unless a loss of body weight is also achieved in this period of time [18]. Other studies concluded that, compared with HDL-C, exercise with a higher intensity is required to reduce the level of LDL-C and TG [19].

Despite many randomized controlled trials (RCTs) related to this topic, the investigated aerobic exercises were limited to walking, cycling, or jogging [7, 9-12, 20, 21]. Very few studies have evaluated the effects of other aerobic exercises such as dancing, mountain climbing, swimming, playing tennis, etc. Moreover, it remains unknown which exercises are more related to a lower risk of dyslipidemia.

To address this issue, we applied data of 95,247 Taiwan Biobank (TWB) participants to evaluate the associations of regular exercise with their TG, LDL-C, HDL-C, and TG/HDL-C levels. The 95,247 TWB subjects were genotyped by one of two single-nucleotide polymorphism arrays. Therefore, by nature, we separated them into a discovery cohort and a replication cohort according to their genotyping arrays.

In this study, we aim to identify exercises that are associated with a lower risk of dyslipidemia according to the discovery cohort, and then we seek replication from the replication cohort. While most previous studies were RCTs with limited sample sizes and exercise kinds [7, 9$12,21]$, this work is an observational study with a much larger sample size and more than 20 kinds of exercise.

\section{Methods}

\section{Taiwan biobank}

From October 2012 to February 2020, TWB recruited 95,247 Taiwan residents aged 30 to 70 years. Among the 95,247 subjects, 27,735 and 67,512 subjects were wholegenome genotyped by the TWB1 and TWB2 genotyping arrays, separately. They were so-called the TWB1 and TWB2 cohorts, respectively [22]. Although the current study includes no genetic analysis, the two cohorts formed a natural separation of a discovery set and a replication set. We here used the 27,735 subjects genotyped by the TWB1 array as the discovery cohort and the 67 , 512 subjects genotyped by the TWB2 array as the replication cohort. After signing informed consent, these 95, 247 community-based volunteers provided blood and urine samples, took physical examinations, and reported lifestyle factors (regular exercise, alcohol drinking, and cigarette smoking) through a face-to-face interview with TWB researchers [23].

TWB was approved by the Institutional Review Board on Biomedical Science Research/IRB-BM, Academia Sinica, and also by the Ethics and Governance Council of Taiwan Biobank, Taiwan. Written informed consent was obtained before data collection, from each participant in accordance with institutional requirements and the principles of the Declaration of Helsinki. Our use of the TWB research data was approved by TWB on February 18, 2020 (application number: TWBR10810-07). This study further received approval from the Research Ethics Committee of National Taiwan University Hospital (NTUH-REC no. 201805050RINB).

\section{Dyslipidemia indices}

We analyzed 3 indices that are related to dyslipidemia: TG, LDL-C, and HDL-C, all measured from serum. HDL-C is considered as "good cholesterol" in the sense that a higher level of HDL-C is linked to a lower risk of coronary heart disease [24]. On the contrary, LDL-C is usually regarded as the "bad" type of cholesterol [25]. A TG level $<150 \mathrm{mg} / \mathrm{dL}$, an LDL-C level $<130 \mathrm{mg} / \mathrm{dL}$, and a HDL-C level $>40 \mathrm{mg} / \mathrm{dL}$ for males or a HDL-C level $>$ $50 \mathrm{mg} / \mathrm{dL}$ for females, are considered desirable [26]. In addition to these 3 dyslipidemia indices, we also investigated TG/HDL-C ratio, which is a useful indicator of 
metabolic syndrome [1]. An elevated TG/HDL-C ratio is strongly associated with an increased risk of adverse cardiac events [27].

\section{Covariates under adjustment}

Sex, age, obesity, alcohol drinking, cigarette smoking, and education level are closely related to dyslipidemia [28]. Therefore, our regression model adjusted sex, age (in years), body mass index (BMI), drinking status (yes vs. no), smoking status (yes vs. no), and educational attainment (a value ranging from 1 to 7 ). In TWB, drinking was defined as a subject having a weekly intake of more than $150 \mathrm{~mL}$ of alcohol for at least 6 months and having not stopped drinking at the time his/her phenotypes were measured. Smoking was defined as a subject who had smoked for at least 6 months and had not quit smoking at the time his/her phenotypes were measured.

Educational attainment was recorded according to a face-to-face interview with TWB researchers, ranging from 1 to 7: 1 "illiterate", 2 "no formal education but literate", 3 "primary school graduate", 4 "junior high school graduate", 5 "senior high school graduate", 6 "college graduate", and 7 "Master's or higher degree".

Regular exercise was defined as performing $30 \mathrm{~min}$ of "exercise" three times a week. "Exercise" includes leisure-time activities such as jogging, swimming, dancing, cycling, mountain climbing, weight training, etc. Individuals with regular exercise would then be asked what kinds of exercise they usually engaged in.

\section{Statistical analysis}

To investigate exercise effects on the 4 dyslipidemia indices, we considered the following regression model:

$$
\begin{aligned}
Y_{k}= & \beta_{0}+\sum_{j=1}^{23} \beta_{E_{j, k}} E_{j}+\sum_{v=1}^{6} \beta_{C_{v}} \text { Covariate }_{v} \\
& +\varepsilon
\end{aligned}
$$

where $Y_{k}$ is dyslipidemia index $k(k=1,2,3$, or 4$), E_{j}$ is an indicator variable taking a value of 1 or $0\left(E_{j}=1\right.$ if the subject chose exercise $j$ as the regular exercise, and $j=1, \cdots, 23)$, Covariate $_{v}$ is the $v^{\text {th }}$ covariate $(v=1, \cdots, 6)$, and $\varepsilon$ is the random error term. Exercise $j$ will be claimed to exhibit effects on index $k$ if the $p$-value of $H_{0}$ $: \beta_{E_{j, k}}=0$ vs. $H_{1}: \beta_{E_{j, k}} \neq 0$ is less than $\frac{0.05}{(30 \times 4)}=0.0004$, which is the Bonferroni-corrected significance level considering 30 regression coefficients $\left(\beta_{0}, \beta_{E_{i, k}}\right.$, and $\left.\beta_{C_{v}}\right)$ in model (1) and 4 dyslipidemia indices. All analyses were performed using $\mathrm{R}$ version 4.0.3.

\section{Results}

Basic characteristics of the TWB subjects

Among the 95,247 TWB subjects, 27,735 were classified into the discovery cohort whereas 67,512 the replication cohort. Table 1 presents the basic characteristics of these two cohorts, stratified by sexes. The discovery (replication) cohort shows that $28.6 \%(29.6 \%)$ males and $13.8 \%$ (15.9\%) females had TG $>150 \mathrm{mg} / \mathrm{dL} ; 38.3 \%$ (36.4\%) males and $33.6 \%(35.3 \%)$ females had LDL-C $>130 \mathrm{mg} /$

\begin{tabular}{|c|c|c|c|c|}
\hline & \multicolumn{2}{|l|}{ Males } & \multicolumn{2}{|l|}{ Females } \\
\hline & Discovery cohort & Replication cohort & Discovery cohort & Replication cohort \\
\hline Total & $13,834(49.9)$ & $20,763(30.8)$ & $13,901(50.1)$ & $46,749(69.2)$ \\
\hline Age (years) & $48.8 \pm 11.2$ & $50.8 \pm 11.3$ & $48.8 \pm 11.1$ & $50.3 \pm 10.5$ \\
\hline BMI $\left(\mathrm{kg} / \mathrm{m}^{2}\right)$ & $25.2 \pm 3.5$ & $25.4 \pm 3.5$ & $23.5 \pm 3.7$ & $23.6 \pm 3.7$ \\
\hline Drinking & $1714(12.4)$ & $2740(13.2)$ & $246(1.8)$ & $841(1.8)$ \\
\hline Smoking & $2886(20.9)$ & $4351(21.0)$ & $397(2.9)$ & $1334(2.9)$ \\
\hline Educational attainment & $5.7 \pm 0.9$ & $5.7 \pm 0.9$ & $5.3 \pm 1.0$ & $5.3 \pm 1.0$ \\
\hline TG (mg/dL) & $133.8 \pm 104.5$ & $140.3 \pm 127.8$ & $99.4 \pm 68.6$ & $103.4 \pm 73.8$ \\
\hline $\mathrm{TG}>150 \mathrm{mg} / \mathrm{dL}$ & 3951 (28.6) & 6151 (29.6) & $1916(13.8)$ & $7434(15.9)$ \\
\hline LDL-C (mg/dL) & $122.3 \pm 31.4$ & $121.0 \pm 31.3$ & $119.4 \pm 31.9$ & $120.6 \pm 31.8$ \\
\hline LDL-C > 130 mg/dL & $5295(38.3)$ & $7555(36.4)$ & 4676 (33.6) & $16,488(35.3)$ \\
\hline $\mathrm{HDL}-\mathrm{C}(\mathrm{mg} / \mathrm{dL})$ & $47.9 \pm 11.0$ & $47.8 \pm 11.1$ & $58.0 \pm 13.1$ & $58.1 \pm 13.2$ \\
\hline $\mathrm{HDL}-\mathrm{C}<40 \mathrm{mg} / \mathrm{dL}$ (males) & $3137(22.7)$ & $4815(23.2)$ & - & - \\
\hline $\mathrm{HDL}-\mathrm{C}<50$ mg/dL (females) & - & - & 3837 (27.6) & $12,980(27.8)$ \\
\hline TG/HDL-C & $3.2 \pm 3.4$ & $3.3 \pm 4.4$ & $1.9 \pm 1.9$ & $2.0 \pm 2.1$ \\
\hline $\mathrm{TG} / \mathrm{HDL}-\mathrm{C}>3.75$ (males) $^{\mathrm{a}}$ & $3572(25.8)$ & $5622(27.1)$ & - & - \\
\hline $\mathrm{TG} / \mathrm{HDL}-\mathrm{C}>3$ (females) $^{\mathrm{a}}$ & - & - & $2093(15.1)$ & $7856(16.8)$ \\
\hline
\end{tabular}

Table 1 Basic characteristics of the 95,247 Taiwan Biobank subjects

Data are shown in $n(\%)$ or mean \pm SD

${ }^{\mathrm{a} C}$ Combining TG and HDL-C, the undesirable range for TG/HDL-C is $>3.75$ (= 150/40, for male) or $>3$ (= 150/50, for female) 


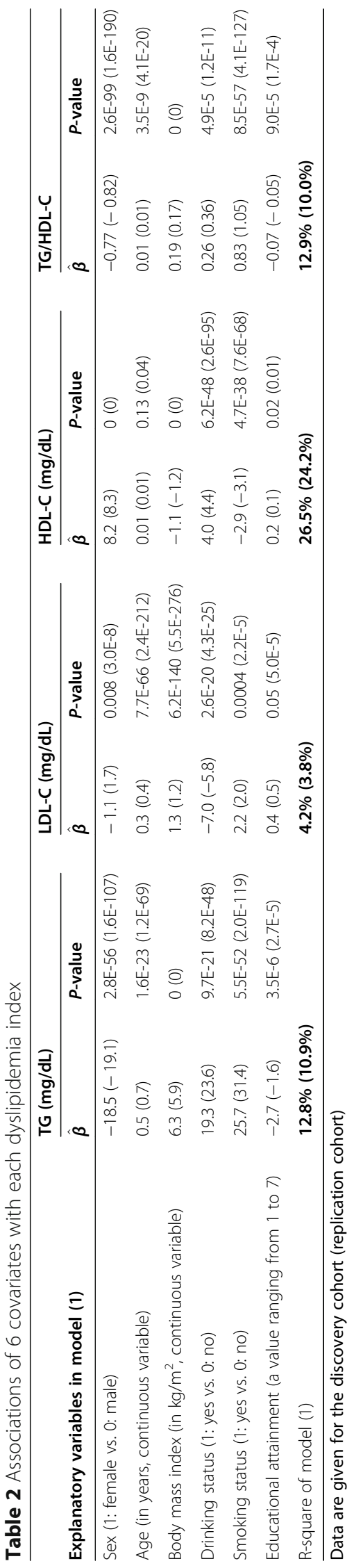




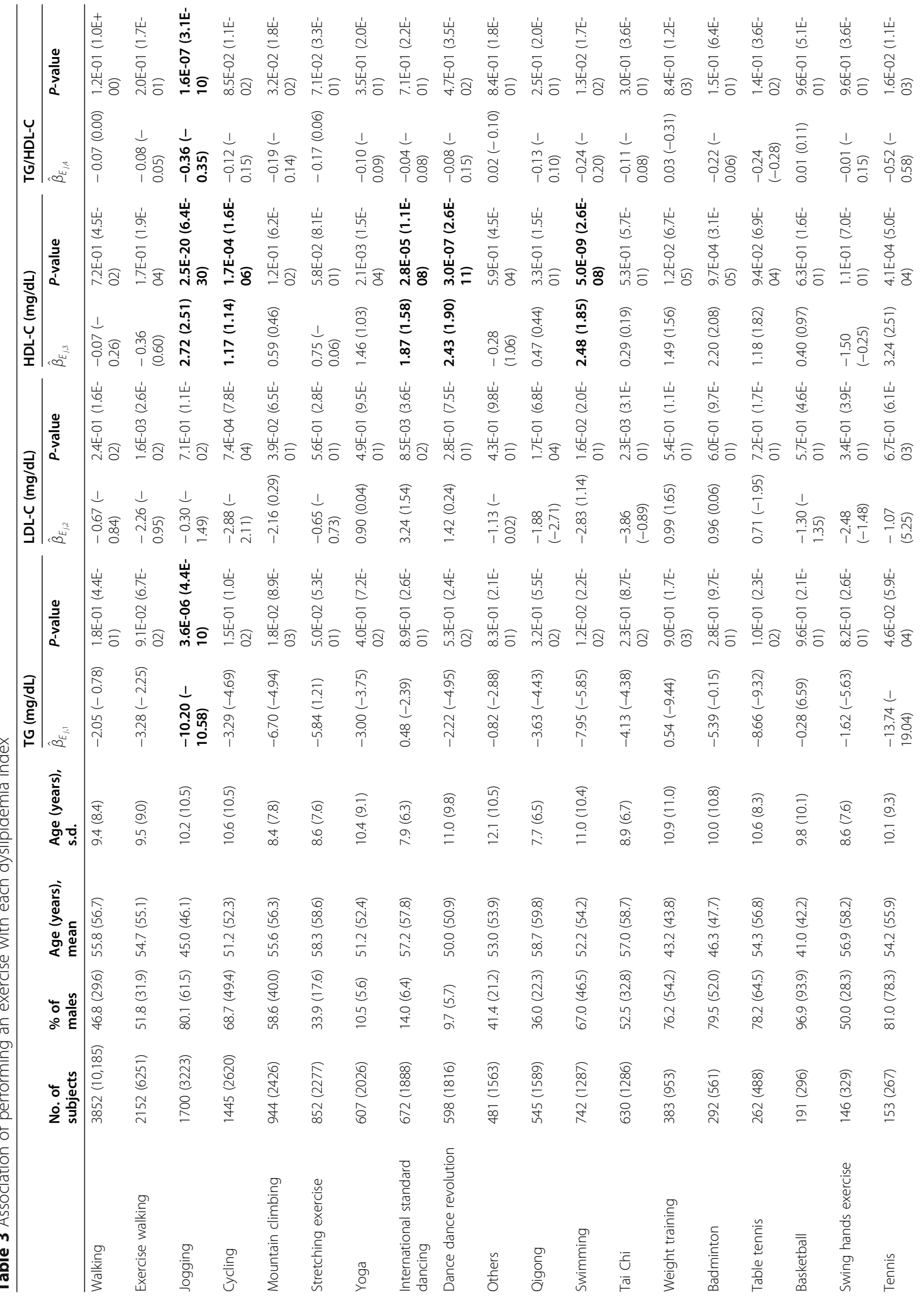




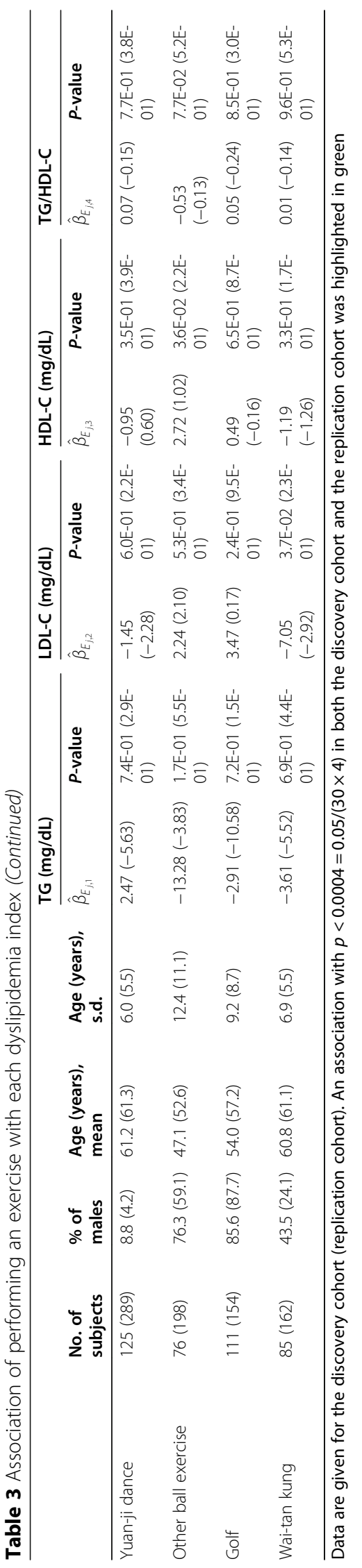




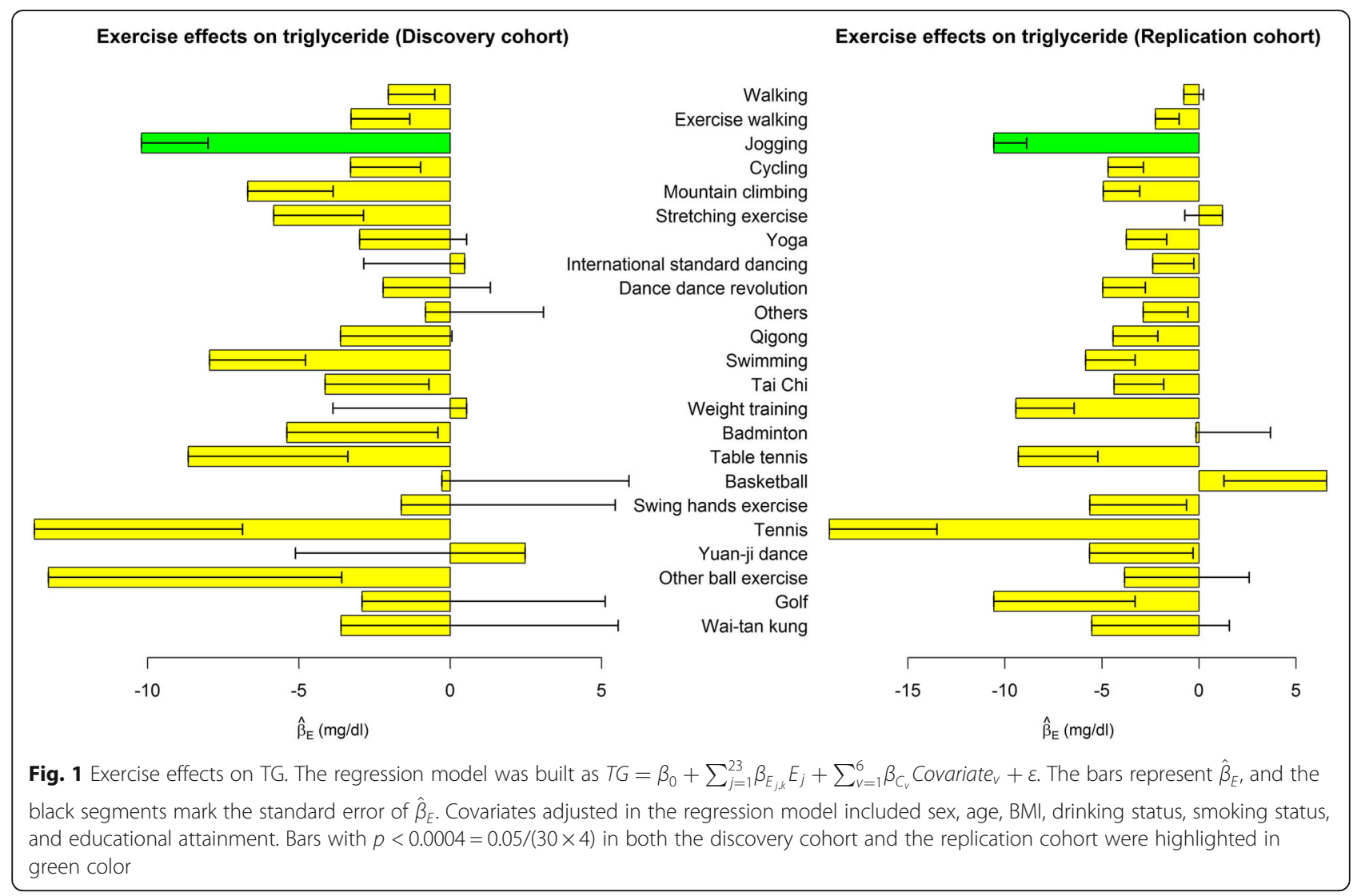

Exercise effects on LDL cholesterol (Discovery cohort)

Exercise effects on LDL cholesterol (Replication cohort)
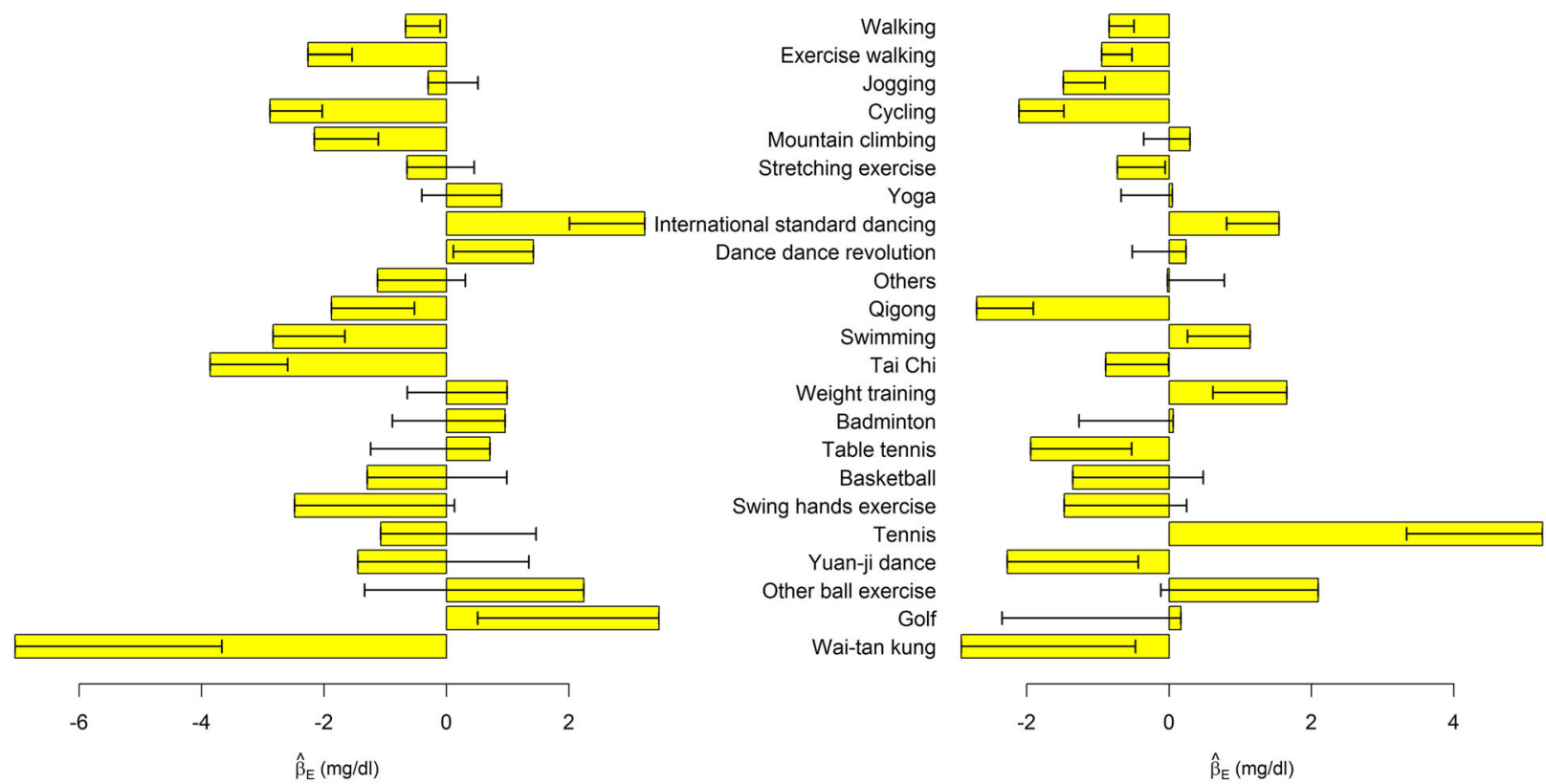

Fig. 2 Exercise effects on $L D L-C$. The regression model was built as $L D L-C=\beta_{0}+\sum_{j=1}^{23} \beta_{E_{j, k}} E_{j}+\sum_{v=1}^{6} \beta_{C_{v}}$ Covariate $e_{v}+\varepsilon$. The bars represent $\hat{\beta}_{E}$, and the black segments mark the standard error of $\hat{\beta}_{E}$. Covariates adjusted in the regression model included sex, age, BMI, drinking status, smoking status, and educational attainment. Bars with $p<0.0004=0.05 /(30 \times 4)$ in both the discovery cohort and the replication cohort were highlighted in green color 


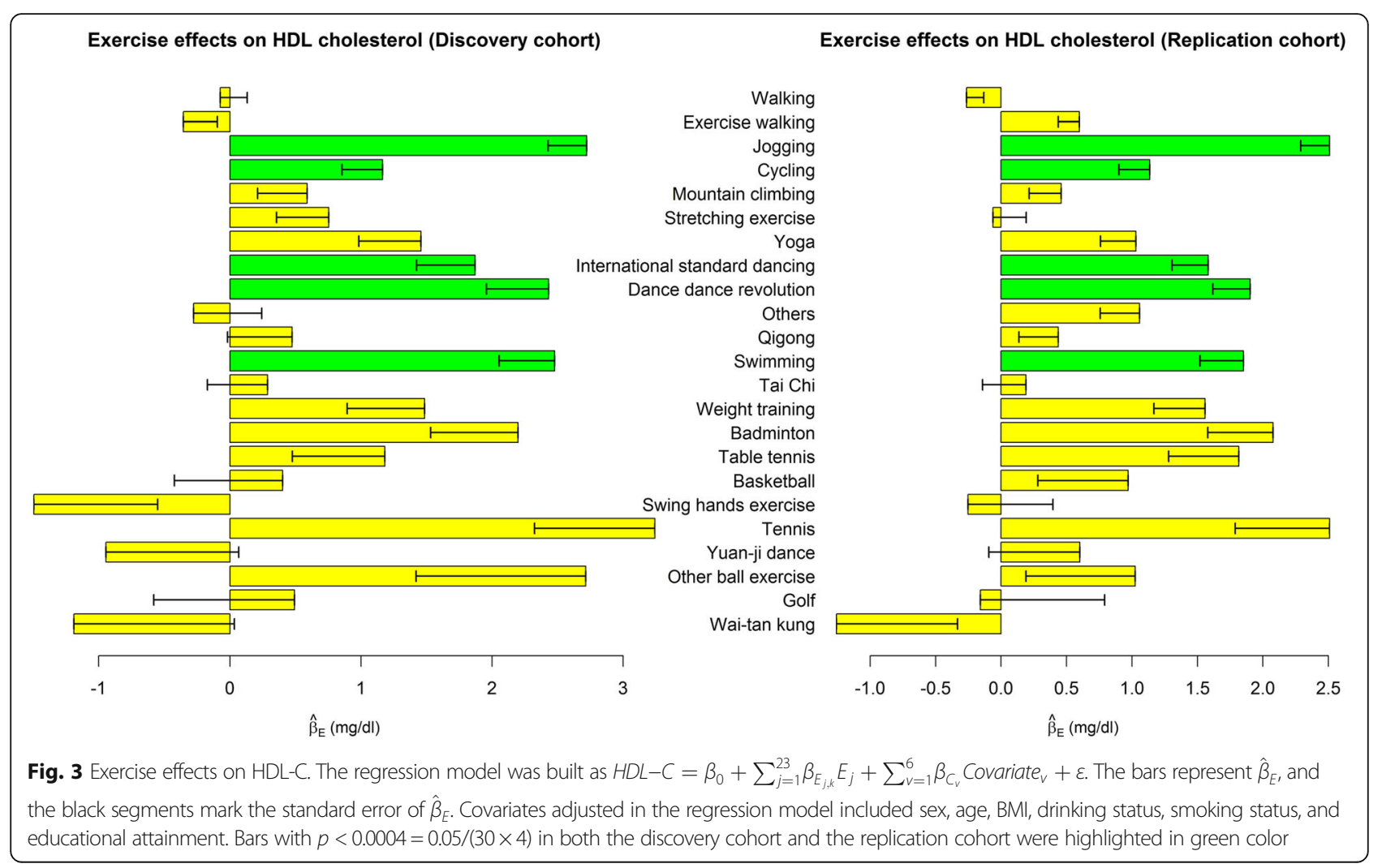

\section{Exercise effects on TG/HDL-C (Discovery cohort)}

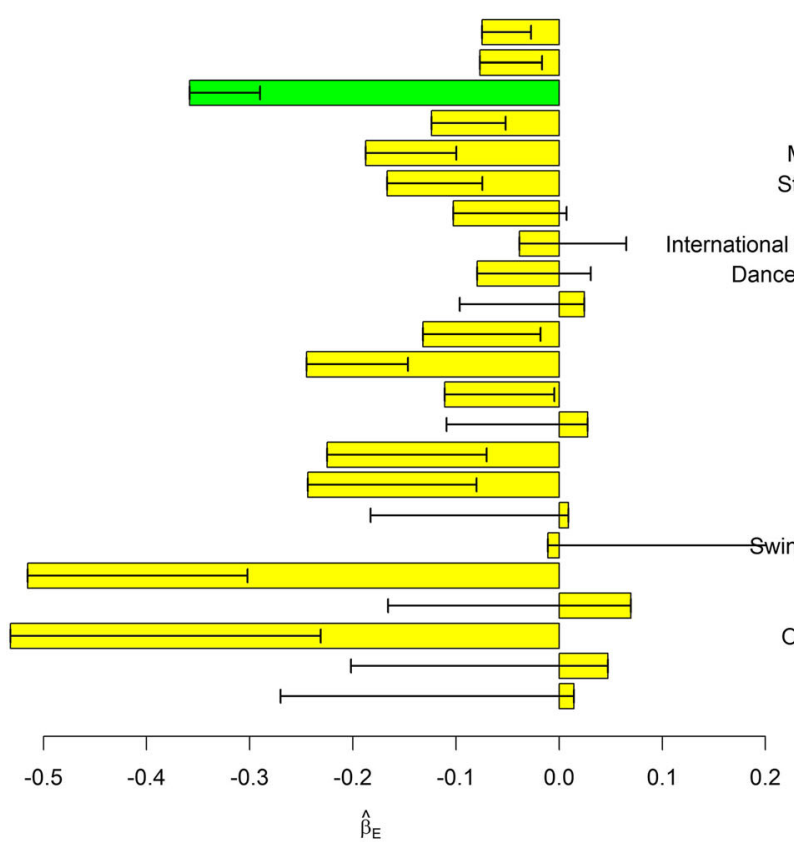

\section{Exercise effects on TG/HDL-C (Replication cohort)}

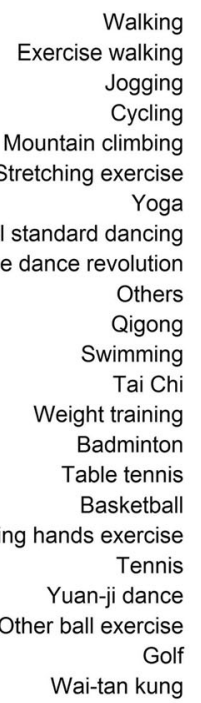

Wai-tan kung

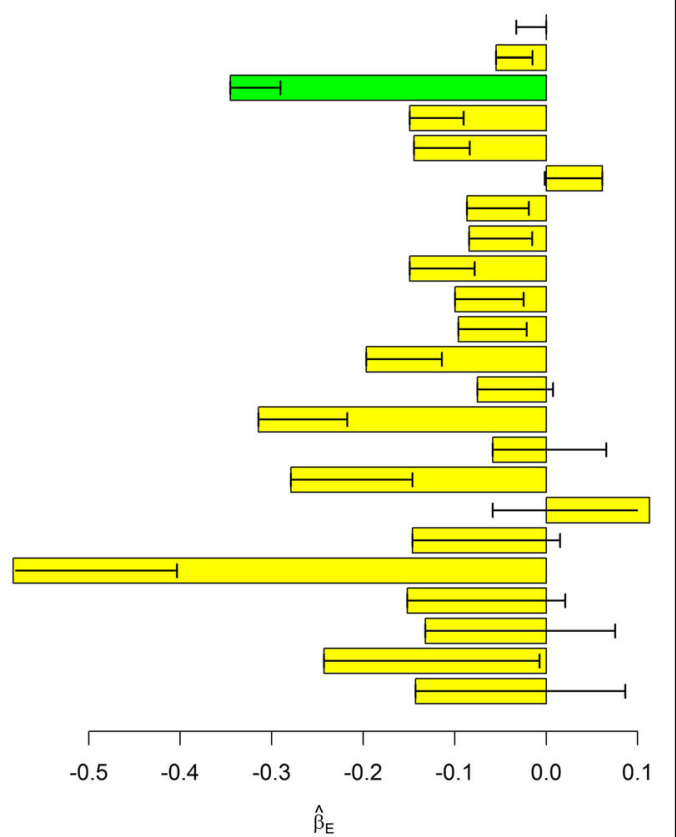

Fig. 4 Exercise effects on TG/HDL-C. The regression model was built as TG/HDL-C $=\beta_{0}+\sum_{j=1}^{23} \beta_{E_{j . k}} E_{j}+\sum_{v=1}^{6} \beta_{C_{v}}$ Covariate $_{v}+\varepsilon$. The bars represent $\hat{\beta}_{E}$, and the black segments mark the standard error of $\hat{\beta}_{E}$. Covariates adjusted in the regression model included sex, age, BMI, drinking status, smoking status, and educational attainment. Bars with $p<0.0004=0.05 /(30 \times 4)$ in both the discovery cohort and the replication cohort were highlighted in green color 
$\mathrm{dL} ; 22.7 \%$ (23.2\%) males had $\mathrm{HDL}-\mathrm{C}<40 \mathrm{mg} / \mathrm{dL}$ and $27.6 \%$ (27.8\%) females had HDL-C $<50 \mathrm{mg} / \mathrm{dL}$. The replication cohort presents similar results (Table 1).

To assess exercise effects while adjusting for covariates, we fitted model (1) for the 4 dyslipidemia indices, respectively. The results were presented in Tables 2 and 3. We used the "car" package (https:// cran.r-project.org/web/packages/car/) to compute variance inflation factor (VIF). The VIFs under 8 models (4 dyslipidemia indices in 2 cohorts) were all smaller than 2. This suggests that multicollinearity between variables in model (1) is acceptable.

Table 2 shows the associations of 6 covariates with each dyslipidemia index, respectively. As mentioned above, a $p$-value less than 0.0004 is considered significant throughout this work. Female had a lower mean TG by $18.5 \mathrm{mg} / \mathrm{dL}$ (95\% confidence interval [C.I.] $=16.2-20.8$ ) and a higher mean HDL-C by 8.2 $\mathrm{mg} / \mathrm{dL}(95 \%$ C.I. $=7.9-8.5)$ than males. Elder subjects had increased TG and LDL-C levels than younger subjects, but no significant association of age with HDL-C was observed ( $p=0.13$ and 0.04 in the discovery cohort and the replication cohort, respectively).

A strong association was found in BMI and all indices. A larger BMI was associated with increased TG, and LDL-C levels, and a decreased HDL-C level. Alcohol drinking was associated with elevated TG and HDL$\mathrm{C}$ levels, and a decreased LDL-C level. The relationship between alcohol consumption and health outcomes remains controversial. On the contrary, cigarette smoking is consistently adverse to health by being associated with increased TG and LDL-C levels, and decreased HDL-C level. A higher education attainment was associated with a lower TG level.

\section{Associations of performing exercises with dyslipidemia indices}

Table 3 shows the associations of performing each exercise with 4 dyslipidemia indices, respectively. We also presented the effect sizes $\left(\hat{\beta}_{E_{j, k}}\right.$ in model $(1)$, where $j=1$ $, \cdots, 23, k=1, \cdots, 4)$ in Figs. 1, 2, 3 and 4. Performing exercise was generally associated with a decreased level in TG (Fig. 1) and an increased level in HDL-C (Fig. 3). However, no significant associations were detected between any exercise and LDL-C (Table 3 and Fig. 2).

Subjects choosing jogging as their regular exercise had a lower TG level by $10.2 \mathrm{mg} / \mathrm{dL}(95 \%$ C.I. $=5.9-14.5)$, a higher HDL-C level by $2.7 \mathrm{mg} / \mathrm{dL}(95 \%$ C.I. $=2.1-3.3$ ), and a decreased TG/HDL-C ratio by 0.36 (95\% C.I. $=$ $0.22-0.49)$. Moreover, swimming (95\% C.I. $=1.6-3.3$ ), dance dance revolution (DDR) $(95 \%$ C.I. $=1.5-3.4)$, international standard dancing (95\% C.I. $=1.0-2.7)$, and cycling (95\% C.I. $=0.6-1.8)$ were associated with an increased level in HDL-C. These significant findings were well replicated in the TWB2 cohort, and the effect sizes $\left(\hat{\beta}_{E_{j, k}}\right.$ in model $(1)$, where $\left.j=1, \cdots, 23, k=1, \cdots, 4\right)$ were similar across the TWB1 and TWB2 cohorts (Table 3).

\section{Discussion}

This is a large-scale observational study evaluating the associations of regularly performing physical exercises with lipoprotein-lipid profiles. In line with the previous studies [4, 19], we here also found that HDL-C is the most sensitive index to exercise among the 3 dyslipidemia measures. Performing regular exercise has been found to improve HDL-C functionality, including cholesterol efflux capacity, anti-oxidative, and anti-inflammatory properties [17]. Cholesterol efflux capacity is a measure of the ability for a subject's HDL-C to extract cholesterol from macrophages [29]. Moreover, exercise elevates lipid peroxide transport function of HDL-C $[17,30]$. Finally, exercise training increased the ability of HDL-C to protect endothelial cells from injury [31].

Existing evidence on LDL-C response to aerobic exercises remains contradictory and inconsistent [9-12]. A number of studies have concluded that exercise has little effect on LDL-C unless combined with dietary change and weight loss $[4,32-34]$. In this work, we have not found any significant association between LDL-C and physical exercise (Fig. 2).

Some RCTs have investigated exercise effects on dyslipidemia [20]. RCTs are usually small to medium in sample sizes, say, from 12 to 111 subjects [7, 9-12, 21]. Moreover, the kinds of exercise examined in RCTs are typically limited [7]. For example, LeMura et al. compared aerobic exercise with "resistance exercise" (or "strength training") [9]. In that study, aerobic exercise included cycling, walking, and jogging; resistance exercise indicated weight training [9]. In a meta-analysis evaluating the efficacy of aerobic exercises on HDL-C [7], 22 out of 25 RCTs investigated the effects of walking, jogging, or cycling. Among aerobic exercises, these three kinds of exercise were commonly studied.

In this study, all the 5 exercises found to be associated with a healthier lipoprotein-lipid profile (i.e., jogging, swimming, DDR, international standard dancing, and cycling, as shown in Fig. 3) were examples of aerobic exercise. Another type of exercise, resistance exercise such as weight training, has not been found to improve people's lipoprotein-lipid profile [9]. In line with this previous finding [9], we here did not observe any significant association between weight training and the 4 dyslipidemia indices. 
While resistance exercise aims at increasing strength of muscles, aerobic exercise increases oxygen consumption without significantly changing strength $[35,36]$. Aerobic exercise increases the activity of lipoprotein lipase (LPL) [37, 38], an enzyme produced by skeletal muscles and adipose tissues [39]. LPL can reduce circulating TG in the bloodstream [40]. Among aerobic exercises, jogging is especially a full-body exercise involving many body parts. To jog, one's arms swing, legs and feet run, shoulders and abdomen are also involved in this continuous movement. As an aerobic endurance exercise, jogging can more effectively boost oxygen consumption and blood circulation [41]. A jogging training lasting for 12 weeks has been shown to increase serum LPL concentrations [42], which further facilitates the clearance of circulating TG and elevation of HDL-C level [43].

A limitation of this work is that exercise intensity (usually monitored by the percentage of one's maximum heart rate) could not be monitored as what was done in RCTs. Although this is an observational study and all signals were explained as associations, many of our results were consistent with the results from previous RCTs [9-12]. Moreover, this is the first large-scale observational study linking various kinds of physical exercise to people's lipoprotein-lipid profile.

\section{Conclusion}

Our significant findings here were identified by the discovery cohort of 27,735 subjects and further well replicated by the replication cohort of 67,512 subjects. Through our analysis, we showed that regular jogging was not only associated with an increased level of HDL$\mathrm{C}$, but also the only one exercise associated with a decreased level of TG and TG/HDL-C ratio. Nonetheless, jogging may be difficult to engage in for subjects with limited exercise capacity. We here found that swimming, dancing (including DDR and international standard dancing), and cycling are also significantly associated with an increased level of HDL-C. People who are seeking exercise to improve their lipoprotein-lipid profiles can have other choices now.

\section{Abbreviations}

DDR: Dance dance revolution; HDL-C: High-density lipoprotein cholesterol; LDL-C: Low-density lipoprotein cholesterol; RCT: Randomized controlled trial; TWB: Taiwan Biobank; TG: Triglyceride

\section{Acknowledgments}

The author would like to thank the three anonymous reviewers for their insightful and constructive comments, and the Taiwan Biobank for approving our application to access the data.

\section{Author's contributions}

W.-Y.L. conceived the study design, applied for the Taiwan Biobank (TWB) data, developed the analysis tool, analyzed the TWB data, and wrote the manuscript. The author read and approved the final manuscript.

\section{Funding}

This study was supported by the Ministry of Science and Technology of Taiwan (grant number MOST 107-2314-B-002-195-MY3 to W.-Y.L.).

\section{Availability of data and materials}

The datasets analyzed during the current study are available from the Taiwan Biobank, https://www.twbiobank.org.tw/new_web_en/index.php

\section{Declarations}

\section{Ethics approval and consent to participate}

Taiwan Biobank (TWB) was approved by the Institutional Review Board on Biomedical Science Research/IRB-BM, Academia Sinica, and also by the Ethics and Governance Council of Taiwan Biobank, Taiwan. Written informed consent was obtained before data collection, from each participant in accordance with institutional requirements and the principles of the Declaration of Helsinki. Our use of the TWB research data was approved by TWB on February 18, 2020 (application number: TWBR10810-07). This study further received approval from the Research Ethics Committee of National

Taiwan University Hospital (NTUH-REC no. 201805050RINB).

\section{Consent for publication}

Not applicable. This manuscript does not contain any individual details, images or videos. Only aggregate data were used in this work.

\section{Competing interests}

The authors declare that they have no competing interests.

Received: 8 December 2020 Accepted: 26 April 2021

Published online: 10 May 2021

\section{References}

1. Borrayo G, Basurto L, Gonzalez-Escudero E, Diaz A, Vazquez A, Sanchez L, et al. Tg/Hdl-C ratio as cardio-metabolic biomarker even in Normal weight women. Acta Endocrinol-Buch. 2018;14(2):261-7.

2. Backes J, Anzalone D, Hilleman D, Catini J. The clinical relevance of omega-3 fatty acids in the management of hypertriglyceridemia. Lipids Health Dis. 2016;15(1):118. https://doi.org/10.1186/s12944-016-0286-4.

3. Grandjean PW, Crouse SF, Rohack JJ. Influence of cholesterol status on blood lipid and lipoprotein enzyme responses to aerobic exercise. J Appl Physiol (1985). 2000;89(2):472-80.

4. Wang Y, Xu D. Effects of aerobic exercise on lipids and lipoproteins. Lipids Health Dis. 2017;16(1):132. https://doi.org/10.1186/s12944-017-0515-5.

5. Sarzynski MA, Ruiz-Ramie JJ, Barber JL, Slentz CA, Apolzan JW, McGarrah RW, et al. Effects of increasing exercise intensity and dose on multiple measures of HDL (high-density lipoprotein) function. Arterioscler Thromb Vasc Biol. 2018;38(4):943-52.

6. Durstine JL, Grandjean PW, Davis PG, Ferguson MA, Alderson NL, DuBose KD. Blood lipid and lipoprotein adaptations to exercise: a quantitative analysis. Sports Med. 2001;31(15):1033-62. https://doi.org/10.2165/000072 56-200131150-00002.

7. Kodama S, Tanaka S, Saito K, Shu M, Sone Y, Onitake F, et al. Effect of aerobic exercise training on serum levels of high-density lipoprotein cholesterol: a meta-analysis. Arch Intern Med. 2007;167(10):999-1008. https://doi.org/10.1001/archinte.167.10.999.

8. Kokkinos PF, Holland JC, Narayan P, Colleran JA, Dotson CO, Papademetriou $\checkmark$. Miles run per week and high-density lipoprotein cholesterol levels in healthy, middle-aged men. A dose-response relationship. Arch Intern Med. 1995;155(4):415-20.

9. LeMura LM, von Duvillard SP, Andreacci J, Klebez JM, Chelland SA, Russo J. Lipid and lipoprotein profiles, cardiovascular fitness, body composition, and diet during and after resistance, aerobic and combination training in young women. Eur J Appl Physiol. 2000;82(5-6):451-8. https://doi.org/10.1007/ s004210000234.

10. Nybo L, Sundstrup E, Jakobsen MD, Mohr M, Hornstrup T, Simonsen L, et al. High-intensity training versus traditional exercise interventions for promoting health. Med Sci Sports Exerc. 2010;42(10):1951-8. https://doi. org/10.1249/MSS.0b013e3181d99203.

11. Kraus WE, Houmard JA, Duscha BD, Knetzger KJ, Wharton MB, McCartney JS, et al. Effects of the amount and intensity of exercise on plasma lipoproteins. N Engl J Med. 2002;347(19):1483-92. https://doi.org/10.1056/NEJMoa020194. 
12. O'Donovan G, Owen A, Bird SR, Kearney EM, Nevill AM, Jones DW, et al. Changes in cardiorespiratory fitness and coronary heart disease risk factors following 24 wk of moderate- or high-intensity exercise of equal energy cost. J Appl Physiol (1985). 2005;98(5):1619-25.

13. Hsu CS, Chang ST, Nfor ON, Lee KJ, Lee SS, Liaw YP. Effects of regular aerobic exercise and resistance training on high-density lipoprotein cholesterol levels in Taiwanese adults. Int J Environ Res Public Health. 2019; 16(11):2003. https://doi.org/10.3390/ijerph16112003.

14. Kazeminasab F, Marandi M, Ghaedi K, Esfarjani F, Moshtaghian J. Endurance training enhances LXRalpha gene expression in Wistar male rats. Eur J Appl Physiol. 2013;113(9):2285-90. https://doi.org/10.1007/s00421-013-2658-z.

15. Ghanbari-Niaki A, Khabazian BM, Hossaini-Kakhak SA, Rahbarizadeh F, Hedayati M. Treadmill exercise enhances ABCA1 expression in rat liver. Biochem Biophys Res Commun. 2007;361(4):841-6. https://doi.org/10.1016/j. bbrc.2007.07.100.

16. Kazeminasab F, Marandi M, Ghaedi K, Esfarjani F, Moshtaghian J. Effects of a 4-week aerobic exercise on lipid profile and expression of LXRalpha in rat liver. Cell J. 2017;19(1):45-9. https://doi.org/10.22074/cellj.2016.4871.

17. Ruiz-Ramie JJ, Barber JL, Sarzynski MA. Effects of exercise on HDL functionality. Curr Opin Lipidol. 2019;30(1):16-23. https://doi.org/10.1097/ MOL.0000000000000568.

18. Goldberg AC, Hopkins PN, Toth PP, Ballantyne CM, Rader DJ, Robinson JG, et al. Familial hypercholesterolemia: screening, diagnosis and management of pediatric and adult patients: clinical guidance from the National Lipid Association Expert Panel on familial hypercholesterolemia. J Clin Lipidol. 2011;5(3 Suppl):S1-8. https://doi.org/10.1016/j.jacl.2011.04.003.

19. Mann S, Beedie C, Jimenez A. Differential effects of aerobic exercise, resistance training and combined exercise modalities on cholesterol and the lipid profile: review, synthesis and recommendations. Sports Med. 2014; 44(2):211-21. https://doi.org/10.1007/s40279-013-0110-5.

20. Kelley GA, Kelley KS. Aerobic exercise and HDL2-C: a meta-analysis of randomized controlled trials. Atherosclerosis. 2006;184(1):207-15. https://doi. org/10.1016/j.atherosclerosis.2005.04.005.

21. Sugiura H, Sugiura H, Kajima K, Mirbod SM, Iwata H, Matsuoka T. Effects of long-term moderate exercise and increase in number of daily steps on serum lipids in women: randomised controlled trial [ISRCTN21921919]. BMC Womens Health. 2002;2(1):3. https://doi.org/10.1186/1472-6874-2-3.

22. Lin WY, Liu YL, Yang AC, Tsai SJ, Kuo PH. Active cigarette smoking is associated with an exacerbation of genetic susceptibility to diabetes. Diabetes. 2020;69(12):2819-29.

23. Chen $\mathrm{CH}$, Yang JH, Chiang CWK, Hsiung CN, Wu PE, Chang LC, et al. Population structure of Han Chinese in the modern Taiwanese population based on 10,000 participants in the Taiwan biobank project. Hum Mol Genet. 2016;25(24):5321-31. https://doi.org/10.1093/hmg/ddw346.

24. Marz W, Kleber ME, Scharnagl H, Speer T, Zewinger S, Ritsch A, et al. HDL cholesterol: reappraisal of its clinical relevance. Clin Res Cardiol. 2017;106(9): 663-75. https://doi.org/10.1007/s00392-017-1106-1.

25. Elshourbagy NA, Meyers HV, Abdel-Meguid SS. Cholesterol: the good, the bad, and the ugly - therapeutic targets for the treatment of dyslipidemia. Med Princ Pract. 2014;23(2):99-111. https://doi.org/10.1159/000356856.

26. Lee JS, Chang PY, Zhang Y, Kizer JR, Best LG, Howard BV. Triglyceride and $\mathrm{HDL}-\mathrm{C}$ dyslipidemia and risks of coronary heart disease and ischemic stroke by glycemic Dysregulation status: the strong heart study. Diabetes Care. 2017:40(4):529-37. https://doi.org/10.2337/dc16-1958.

27. Sultani R, Tong DC, Peverelle M, Lee YS, Baradi A, Wilson AM. Elevated triglycerides to high-density lipoprotein cholesterol (TG/HDL-C) ratio predicts long-term mortality in high-risk patients. Heart Lung Circ. 2020; 29(3):414-21. https://doi.org/10.1016/j.hlc.2019.03.019.

28. Qi L, Ding X, Tang W, Li Q, Mao D, Wang Y. Prevalence and risk factors associated with dyslipidemia in Chongqing, China. Int J Environ Res Public Health. 2015;12(10):13455-65. https://doi.org/10.3390/ijerph121013455.

29. Khera AV, Demler OV, Adelman SJ, Collins HL, Glynn RJ, Ridker PM, et al. Cholesterol efflux capacity, high-density lipoprotein particle number, and incident cardiovascular events: an analysis from the JUPITER trial (justification for the use of statins in prevention: an intervention trial evaluating Rosuvastatin). Circulation. 2017;135(25):2494-504. https://doi. org/10.1161/CIRCULATIONAHA.116.025678.

30. Tiainen S, Luoto R, Ahotupa M, Raitanen J, Vasankari T. 6-mo aerobic exercise intervention enhances the lipid peroxide transport function of $\mathrm{HDL}$. Free Radic Res. 2016;50(11):1279-85. https://doi.org/10.1080/10715762.201 6.1252040.
31. Sang H, Yao S, Zhang L, Li X, Yang N, Zhao J, et al. Walk-run training improves the anti-inflammation properties of high-density lipoprotein in patients with metabolic syndrome. J Clin Endocrinol Metab. 2015;100(3): 870-9. https://doi.org/10.1210/jc.2014-2979.

32. Nieman DC, Brock DW, Butterworth D, Utter AC, Nieman CC. Reducing diet and/or exercise training decreases the lipid and lipoprotein risk factors of moderately obese women. J Am Coll Nutr. 2002;21(4):344-50. https://doi. org/10.1080/07315724.2002.10719233.

33. Katzel LI, Bleecker ER, Colman EG, Rogus EM, Sorkin JD, Goldberg AP. Effects of weight loss vs aerobic exercise training on risk factors for coronary disease in healthy, obese, middle-aged and older men. A randomized controlled trial. JAMA. 1995;274(24):1915-21. https://doi.org/10.1001/jama.1 995.03530240025035.

34. Wood PD. Physical activity, diet, and health: independent and interactive effects. Med Sci Sports Exerc. 1994;26(7):838-43.

35. Lambert CP, Evans WJ. Adaptations to aerobic and resistance exercise in the elderly. Rev Endocr Metab Disord. 2005;6(2):137-43. https://doi.org/10.1007/ s11154-005-6726-5.

36. Villareal DT, Aguirre L, Gurney AB, Waters DL, Sinacore DR, Colombo E, et al. Aerobic or resistance exercise, or both, in dieting obese older adults. New Engl J Med. 2017;376(20):1943-55. https://doi.org/10.1056/NEJMoa1616338.

37. Marandi SM, Abadi NG, Esfarjani F, Mojtahedi H, Ghasemi G. Effects of intensity of aerobics on body composition and blood lipid profile in obese/ overweight females. Int J Prev Med. 2013;4(Suppl 1):S118-25.

38. Fenkci S, Sarsan A, Rota S, Ardic F. Effects of resistance or aerobic exercises on metabolic parameters in obese women who are not on a diet. Adv Ther 2006;23(3):404-13. https://doi.org/10.1007/BF02850161.

39. Wang H, Eckel RH. Lipoprotein lipase: from gene to obesity. Am J Physiol Endocrinol Metab. 2009;297(2):E271-88. https://doi.org/10.1152/ajpendo. 90920.2008.

40. Pirahanchi Y, Anoruo MD, Sharma S. Biochemistry, Lipoprotein Lipase. In: StatPearls: Treasure Island (FL); 2021. https://www.ncbi.nlm.nih.gov/books/ NBK537040/.

41. Radak Z, Zhao Z, Koltai E, Ohno H, Atalay M. Oxygen consumption and usage during physical exercise: the balance between oxidative stress and ROS-dependent adaptive signaling. Antioxid Redox Signal. 2013;18(10): 1208-46. https://doi.org/10.1089/ars.2011.4498.

42. Miyashita M, Eto M, Sasai H, Tsujimoto T, Nomata Y, Tanaka K. Twelve-week jogging training increases pre-heparin serum lipoprotein lipase concentrations in overweight/obese middle-aged men. J Atheroscler Thromb. 2010;17(1):21-9. https://doi.org/10.5551/jat.2337.

43. Pillarisetti $\mathrm{S}$, Saxena U. Lipoprotein lipase as a therapeutic target for dyslipidemia. Front Biosci-Landmrk. 2003:8:D237-41.

\section{Publisher's Note}

Springer Nature remains neutral with regard to jurisdictional claims in published maps and institutional affiliations.

Ready to submit your research? Choose BMC and benefit from:

- fast, convenient online submission

- thorough peer review by experienced researchers in your field

- rapid publication on acceptance

- support for research data, including large and complex data types

- gold Open Access which fosters wider collaboration and increased citations

- maximum visibility for your research: over $100 \mathrm{M}$ website views per year

At $\mathrm{BMC}$, research is always in progress.

Learn more biomedcentral.com/submissions 